University of Nebraska - Lincoln

DigitalCommons@University of Nebraska - Lincoln

Faculty Publications, Department of Psychology

Psychology, Department of

2015

Repeated administration of aripiprazole produces a sensitization effect in the suppression of avoidance responding and phencyclidine-induced hyperlocomotion and increases $\mathrm{D}_{2}$ receptormediated behavioral function

Jun Gao

University of Nebraska-Lincoln

Rongyin Qin

University of Nebraska-Lincoln

Ming Li

University of Nebraska-Lincoln, mli2@unl.edu

Follow this and additional works at: http://digitalcommons.unl.edu/psychfacpub

Part of the Applied Behavior Analysis Commons, Experimental Analysis of Behavior Commons, and the Health Psychology Commons

Gao, Jun; Qin, Rongyin; and Li, Ming, "Repeated administration of aripiprazole produces a sensitization effect in the suppression of avoidance responding and phencyclidine-induced hyperlocomotion and increases $\mathrm{D}_{2}$ receptor-mediated behavioral function" (2015). Faculty Publications, Department of Psychology. 681.

http://digitalcommons.unl.edu/psychfacpub/681

This Article is brought to you for free and open access by the Psychology, Department of at DigitalCommons@University of Nebraska - Lincoln. It has been accepted for inclusion in Faculty Publications, Department of Psychology by an authorized administrator of DigitalCommons@University of Nebraska - Lincoln. 


\title{
Repeated administration of aripiprazole produces a sensitization effect in the suppression of avoidance responding and phencyclidine-induced hyperlocomotion and increases $D_{2}$ receptor-mediated behavioral function
}

\author{
Jun Gao, ${ }^{1}$ Rongyin Qin, ${ }^{1,2,3}$ and Ming $\mathrm{Li}^{1}$
}

1 Department of Psychology, University of Nebraska-Lincoln, Lincoln, NE, USA

2 Department of Neurology, The Clinical Medical College of Yangzhou University, Yangzhou, PR China

3 Department of Neurology, Changzhou No. 2 People's Hospital, Nanjing Medical University, Changzhou, PR China

Corresponding author — Ming Li, Department of Psychology, University of Nebraska-Lincoln, 238 Burnett Hall, Lincoln, NE 68588-0308; email mli2@unl.edu

\begin{abstract}
The present study investigated how repeated administration of aripiprazole (a novel antipsychotic drug) alters its behavioral effects in two behavioral tests of antipsychotic activity and whether this alteration is correlated with an increase in dopamine $\mathrm{D}_{2}$ receptor function. Male adult Sprague-Dawley rats were first repeatedly tested with aripiprazole $(3,10$ and $30 \mathrm{mg} / \mathrm{kg}$, subcutaneously (sc)) or vehicle in a conditioned avoidance response (CAR) test or a phencyclidine (PCP) $(3.20 \mathrm{mg} / \mathrm{kg}, \mathrm{sc})$-induced hyperlocomotion test daily for five consecutive days. After $2-3$ days of drug-free retraining or resting, all rats were then challenged with aripiprazole (1.5 or $3.0 \mathrm{mg} / \mathrm{kg}$, sc). Repeated administration of aripiprazole progressively increased its inhibition of avoidance responding and PCP-induced hyperlocomotion. More importantly, rats previously treated with aripiprazole showed significantly lower avoidance response and lower PCP-induced hyperlocomotion than those previously treated with vehicle in the challenge tests. An increased sensitivity to quinpirole (a selective $D_{2 / 3}$ agonist) in prior aripiprazole-treated rats was also found in the quinpirole-induced hyperlocomotion test, suggesting an enhanced $\mathrm{D}_{2 / 3}$-mediated function. These findings suggest that aripiprazole, despite its distinct receptor mechanisms of action, induces a sensitization effect similar to those induced by other antipsychotic drugs and this effect may be partially mediated by brain plasticity involving $D_{2 / 3}$ receptor systems.
\end{abstract}

Keywords: Aripiprazole, conditioned avoidance response, phencyclidine, quinpirole, sensitization, tolerance

\section{Introduction}

Patients with schizophrenia take antipsychotic drugs chronically to manage their psychotic symptoms. It is thus of great importance to understand the effects of long-term antipsychotic treatment on brain functions and related psychological functions to better understand the therapeutic and side effects of antipsychotic medications. Many clinical and preclinical studies have reported that chronic administration of antipsychotic drugs often cause either an augmentation or decrease of some of the acute effects of a drug, termed antipsychotic sensitization and tolerance, respectively (Remington and Kapur, 2010; Samaha et al., 2007, 2008; Zhang and Li, 2012). These two phenomena can manifest at multiple levels, including neurotransmitter release, changes in neuroreceptor levels, receptor-mediated second messenger activities, cell electrophysiology, and behaviors, and which can be clinically relevant. For example, haloperidol- induced sensitization has been linked to the gradual development of some extrapyramidal motor side effects (Turrone et al., 2005), increased dopamine supersensitivity (Samaha et al., 2007), and the progressive improvement of psychosis (Agid et al., 2003).

One important issue in the field of antipsychotic sensitization and tolerance is to identify the critical factors that determine the specific patterns of the long-term effects of chronic antipsychotic drug treatment. Among many potential factors, two seem prominent. One is the drug administration schedule (e.g. intermittent vs continuous), as many studies have shown that continuous or frequent drug administration produces some degree of tolerance, while more intermittent injections can result in sensitization (Remington and Kapur, 2010). The second factor is the specific drug type (e.g. clozapine vs olanzapine). In recent years, we have shown that under the same intermittent drug administration schedule, haloperidol, olanzapine, risperidone, and asenapine all produce a sensitization-like effect in their suppres- 
sion of the conditioned avoidance response (CAR) and phencyclidine (PCP)-induced hyperlocomotion (two independent behavioral effects predictive of antipsychotic activity) (Feng et al., 2013; Li et al., 2012; Mead and Li, 2010; Qiao et al., 2013; Qin et al., 2013; Swalve and Li, 2012; Zhang and Li, 2012). However, clozapine produces a tolerance-like effect in these tests (Feng et al., 2013; Li et al., 2010; Qiao et al., 2013). These findings suggest that antipsychotic sensitization and tolerance is also a drug specific phenomenon, in addition to its schedule-dependent feature.

The present study was intended to further examine the drugspecificity issue of antipsychotic sensitization and tolerance by determining what type of repeated effect (sensitization or tolerance) that aripiprazole would induce and whether such an effect is associated with changes in dopamine $D_{2}$ receptor system (Gao and Li, 2013). We are interested in aripiprazole because it is a new antipsychotic drug with a unique pharmacological profile distinct from the conventional and atypical antipsychotics (Mamo et al., 2007). It is a partial 5-hydroxytryptamine 1A (5$\mathrm{HT}_{1 \mathrm{~A}}$ ) receptor agonist and $5-\mathrm{HT}_{2 \mathrm{~A}}$ receptor antagonist, but unlike other antipsychotics, which are potent $D_{2}$ receptor antagonists, aripiprazole has partial agonist activity on these receptors (Bortolozzi et al., 2007; Burris et al., 2002; Jordan et al., 2002). Its long-term effects in animal behavioral tests of antipsychotic drugs have never been assessed and the behavioral pattern (i.e. sensitization or tolerance) it would induce is not known.

In this study, we employed a paradigm that has been validated in our previous CAR and PCP-induced hyperlocomotion work. This paradigm consists of two phases of drug effect assessment: an induction phase and an expression phase (Feng et al., 2013; Li et al., 2010, 2012; Mead and Li, 2010; Qiao et al., 2014; Shu et al., 2014; Swalve and Li, 2012, Zhang and Li, 2012). In the induction phase, rats are repeatedly treated with an antipsychotic drug or vehicle for a certain number of days (e.g. five or seven days), and the drug's suppressive effect on avoidance response and PCP-induced hyperlocomotion is recorded daily. In the expression phase, all rats are given a challenge dose of the drug and tested for avoidance response and PCP-induced hyperlocomotion. Two measures are taken to index the potential sensitization or tolerance effect of the drug. The first index of antipsychotic sensitization/tolerance is obtained from the induction phase and is revealed through a within-subjects comparison, in which the behavioral effect of a drug treatment is stronger/ weaker on the last treatment day than the first day (i.e. a comparison between days 1 and 5). The second index is obtained from the expression phase and is provided by a between-subjects comparison, in which the behavioral response of drug-pretreated animals to a challenge dose of an antipsychotic drug is compared to the response of vehicle- pretreated control animals. Here, antipsychotic sensitization/tolerance is demonstrated by increased/decreased sensitivity to the drug challenge in drugpretreated animals relative to those pretreated with vehicle. In addition, because our recent work suggests that risperidone-induced sensitization in the conditioned avoidance response test is correlated with an increase in $D_{2}$-mediated motor activity, as assessed in the quinipirole (a dopamine $D_{2 / 3}$ receptor agonist)induced hyperlocomotion test (Gao and Li, 2013), we also examined whether repeated aripiprazole would also cause a similar change in $D_{2}$ receptor function.

\section{Materials and method}

\section{Animals}

Adult male Sprague-Dawley rats (226-250 g upon arrival, Charles River, Portage, Michigan, USA) were housed two per cage, in transparent polycarbonate cages $(48.3 \times 26.7 \times 20.3 \mathrm{~cm}$, or $39.5 \times 34.6 \times 21.3 \mathrm{~cm}$ ) under 12 -hour light/dark conditions (light on between 06:00-18:00). Room temperature was maintained at $22 \pm 1^{\circ} \mathrm{C}$ with a relative humidity of $45-60 \%$. Food and water was available ad libitum. Rats were allowed at least five days of habituation to the animal facility before being used in experiments. All behavioral tests took place between 09:00-17:00 in the light cycle. All experimental treatments and procedures were approved by the Institutional Animal Care and Use Committee at the University of Nebraska-Lincoln.

\section{Drugs and choice of doses}

Aripiprazole (gift from the National Institute of Mental Health drug supply program) was dissolved in a mixed double-distilled water solution containing $30 \%(\mathrm{v} / \mathrm{v})$ dimethylformamide and $2 \%$ ( $\mathrm{v} / \mathrm{v}$ ) glacial acetic acid. Doses of aripiprazole (3, 10 and $30 \mathrm{mg} /$ $\mathrm{kg}$ ) were determined based on our previous studies (Li et al., 2005) and reports in the literature (Carli et al., 2011; Cosi et al., 2006; Li et al., 2004; Natesan et al., 2006). These doses of aripiprazole give rise to $71 \%, 85 \%$, and $84 \% \mathrm{D}_{2}$ occupancies, respectively, at one hour post injection (Natesan et al., 2006), but do not cause catalepsy (Hirose et al., 2004). The dose of PCP (3.20 mg/kg) was chosen based on our previous work (Shu et al., 2014; Sun et al., 2009, 2010; Zhang and Li, 2012; Zhao et al., 2012). This dose of PCP is shown to induce a robust hyperlocomotion effect without causing severe stereotypy (Gleason and Shannon, 1997; Kalinichev et al., 2008). The chosen quinpirole dose $(1.0 \mathrm{mg} / \mathrm{kg})$ targets postsynaptic $D_{2 / 3}$ receptors and causes an increase in motor activity (Koller et al., 1987; Luque-Rojas et al., 2013; Nakamura et al., 1994; Prosser et al., 1989). This dose of quinpirole was chosen based on the similar studies from our laboratory (Gao and Li, 2013; Qiao et al., 2014). Quinpirole was dissolved in $0.9 \%$ saline. All drugs were administrated subcutaneously (sc) at $1.0 \mathrm{ml} / \mathrm{kg}$.

\section{Apparatus}

Two-way avoidance conditioning apparatus. Eight identical twoway shuttle boxes custom designed and manufactured by Med Associates (St. Albans, Vermont, USA) were used. Each box was housed in a ventilated, sound-insulated isolation cubicle (96.52

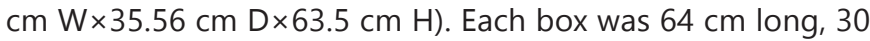
$\mathrm{cm}$ high (from grid floor), and $24 \mathrm{~cm}$ wide, and was divided into two equal-sized compartments by a partition with an arch style doorway $(15 \mathrm{~cm}$ high $\times 9 \mathrm{~cm}$ wide at base). A barrier $(4 \mathrm{~cm}$ high) was placed between the two compartments, so the rats had to jump from one compartment to the other. The grid floor consisted of 40 stainless-steel rods with a diameter of $0.48 \mathrm{~cm}$, spaced $1.6 \mathrm{~cm}$ apart center to center, through which a scrambled footshock (unconditioned stimulus, US, $0.8 \mathrm{~mA}$, maximum duration: $5 \mathrm{~s}$ ) was delivered by a constant current shock generator (Model ENV-410B) and scrambler (Model ENV-412). The rat location and crossings between compartments were monitored by a set of 16 photobeams (ENV-256-8P) affixed at the bottom 
Experiment 1: aripiprazole-induced sensitization in Conditioned avoidance response (CAR) model

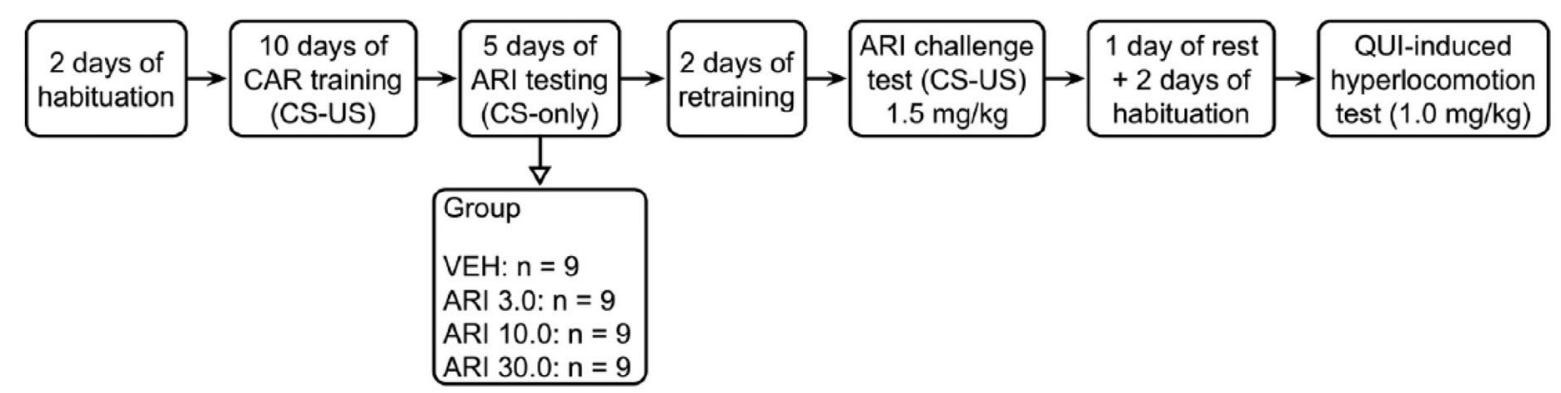

Experiment 2: aripiprazole-induced sensitization in PCP-induced hyperlocomotion model

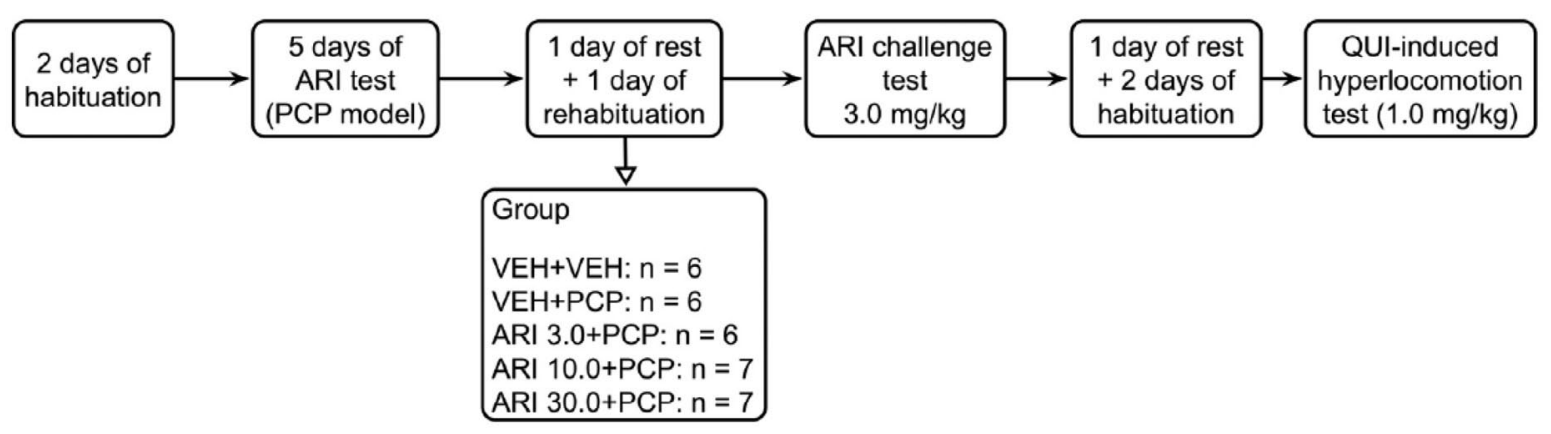

Figure 1. A schematic illustration of the experimental procedure and groups in experiment 1 (conditioned avoidance response (CAR) model) and experiment 2 (phencyclidine (PCP) model). ARI: aripiprazole; CS: conditioned stimulus; QUI: quinpirole; US: unconditioned stimulus; VEH: vehicle.

of the box ( $3.5 \mathrm{~cm}$ above the grid floor). Illumination was provided by two houselights mounted at the top of each compartment. The conditioned stimulus (CS), i.e. $76 \mathrm{~dB}$ white noise) was produced by a speaker (ENV 224 AMX) mounted on the ceiling of the cubicle, centered above the shuttle box. Background noise (approximately $74 \mathrm{~dB}$ ) was provided by a ventilation fan affixed at the top corner of each isolation cubicle. All training and testing procedures were controlled by Med Associates programs running on a computer.

Locomotor activity monitoring apparatus. The motor activity testing apparatus is described in detail before (Feng et al., 2013; Sun et al., 2009; Zhao and Li, 2012). Sixteen activity boxes were housed in a quiet room. The boxes were $48.3 \times 26.7 \times 20.3 \mathrm{~cm}$ transparent polycarbonate cages, which were similar to the home cages but were each equipped with a row of six photocell beams ( $7.8 \mathrm{~cm}$ between two adjacent photobeams) placed $3.2 \mathrm{~cm}$ above the floor of the cage. A computer with recording software (Aero Apparatus Sixbeam Locomotor System v1.4, Toronto, Canada) was used to detect the disruption of the photocell beams and recorded the number of beam breaks. All experiments were run during the light cycle.

\section{Experiment 1: Effect of repeated aripiprazole treatment on avoidance responding}

This experiment examined whether repeated aripiprazole treatment induces a sensitization or tolerance effect in the CAR model and whether this sensitization or tolerance is accompa- nied by dopamine receptor changes. The experiment was comprised of the following three phases: Phase 1: avoidance training and five days of repeated aripiprazole testing; phase 2: aripiprazole challenge test; and phase 3: quinpirole-induced hyperlocomotion test. Figure 1 summarizes the entire experimental procedure and groups at different phases of the experiment.

Phase 1: Avoidance training in CAR and five days of repeated aripiprazole testing. Forty rats were first habituated to the CAR boxes for two days (30 min/day). They were then trained to make avoidance responding for 10 days/sessions. Each session consisted of 30 trials. Every trial started by presenting a white noise (CS) for $10 \mathrm{~s}$, followed by a continuous scrambled foot shock ( 0.8 $m A$, US, maximum duration $=5 \mathrm{~s}$ ) on the grid floor. If a subject moved from one compartment into the other within the $10 \mathrm{~s}$ of CS presentation, it avoided the shock and this shuttling response was recorded as avoidance. If the rat remained in the same compartment for more than $10 \mathrm{~s}$ and made a crossing upon receiving the footshock, this response was recorded as escape. If the rat did not respond during the entire $5 \mathrm{~s}$ presentation of the shock, the trial was terminated and the intertrial intervals started. The total number of avoidance responses was recorded for each session. Intertrial intervals varied randomly between 30 and $60 \mathrm{~s}$.

At the end of the training session, 36 rats reached the training criterion ( $\geq 70 \%$ avoidance in each of the last two sessions). They were first matched on avoidance performance on the last training day (i.e. pre-drug) to create blocks of rats ( $n=4$ rats/ block) that were approximately equal in performance. Within 
each block, they were then randomly assigned to one of four groups: aripiprazole $3 \mathrm{mg} / \mathrm{kg}$ (ARI 3, n=9), aripiprazole $10 \mathrm{mg} /$ $\mathrm{kg}$ (ARI 10, $n=9$ ), aripiprazole $30 \mathrm{mg} / \mathrm{kg}$ (ARI 30, $n=9$ ) and vehicle $(\mathrm{VEH}, n=9)$, and tested daily under the CS-only (no shock, 30 trials/session) condition for five consecutive days, following the same procedure as employed before (Feng et al., 2012, 2013; Swalve and Li, 2012; Zhang and Li, 2012). On each test day, rats were first injected with aripiprazole or vehicle (mixed doubledistilled water solution containing $30 \%(\mathrm{v} / \mathrm{v})$ dimethylformamide and $2 \%(\mathrm{v} / \mathrm{v}$ ) glacial acetic acid), 60 min later, they were placed in the CAR boxes and tested.

Phase 2: Aripiprazole challenge test. One day after the last (5th) aripiprazole test day, all rats were retrained drug-free for one session under the CS-only (no shock) condition, followed by another session under the CS-US condition to bring their avoidance responses back to the pre-drug level. These two retraining sessions also ensured that all groups had a comparable level of avoidance responding before the aripiprazole challenge test, which occurred one day after the 2 nd retraining session. On the challenge day, all rats were injected with aripiprazole at $1.5 \mathrm{mg} /$ $\mathrm{kg}$ and tested for avoidance performance in the CS-only condition (30 trials) 60 min later.

Phase 3: quinpirole-induced hyperlocomotion test. Two days after the aripiprazole challenge test in CAR, all rats were first habituated to the locomotor activity apparatus for two days $(30 \mathrm{~min} /$ day), with the second day preceded by saline injection prior to putting them into the test chambers. One day later, they were injected with quinpirole $(1.0 \mathrm{mg} / \mathrm{kg}, \mathrm{sc})$ and immediately placed in the test apparatus for $120 \mathrm{~min}$. Locomotor activity (number of photobeam breaks) was measured in 10-minute blocks throughout the entire 120-minute test period.

\section{Experiment 2: Effect of repeated aripiprazole treatment on the PCP-induced hyperlocomotion}

This experiment examined how repeated aripiprazole (3.0, 10.0, $30.0 \mathrm{mg} / \mathrm{kg}, \mathrm{sc}$ ) treatment affects the PCP-induced hyperlocomotion. It was designed to examine the generalizability of aripiprazole sensitization across different tests of antipsychotic activity. The entire experiment was comprised of the following three phases: Phase 1: five days of repeated aripiprazole testing; phase 2: aripiprazole challenge test; and phase 3: quinpirole-induced hyperlocomotion test. Figure 1 summarizes the entire experimental procedure and groups at different phases of the experiment.

Phase 1: Five days of repeated aripiprazole testing. Thirtytwo rats were randomly assigned to one of five groups: $\mathrm{VEH}+\mathrm{VEH}$ (vehicle+saline, $n=6$ ), VEH +PCP (vehicle + PCP $3.20 \mathrm{mg} / \mathrm{kg}$, $n=6) ;$ ARI $3.0+P C P(A R I 3.0 \mathrm{mg} / \mathrm{kg}+\mathrm{PCP} 3.20 \mathrm{mg} / \mathrm{kg}, n=6), \mathrm{ARI}$ 10.0+PCP (ARI $10.0 \mathrm{mg} / \mathrm{kg}+$ PCP $3.20 \mathrm{mg} / \mathrm{kg}, n=7)$ and ARI $30.0+P C P$ (ARI $30.0 \mathrm{mg} / \mathrm{kg}+$ PCP $3.20 \mathrm{mg} / \mathrm{kg}, n=7$ ). All rats were first handled and habituated to the locomotor activity apparatus for two days (30 min/day). On each of the next five consecutive days, they were first injected with vehicle $(30 \%(\mathrm{v} / \mathrm{v}) \mathrm{di}-$ methylformamide and $2 \%(\mathrm{v} / \mathrm{v}$ ) glacial acetic acid in water), ARI 3.0, 10.0, $30.0 \mathrm{mg} / \mathrm{kg}$ and then immediately placed in the boxes for $30 \mathrm{~min}$. At the end of the 30-minute period, they were taken out and injected with vehicle (saline) or PCP $(3.20 \mathrm{mg} / \mathrm{kg}, \mathrm{sc}$ ) and placed back in the boxes for another $60 \mathrm{~min}$. Locomotor activity (number of photobeam breaks) was measured in 5 min intervals throughout the entire 90-minute testing session.

Phase 2: Aripiprazole challenge test. Two days after the last (5th) ARI test, all rats were returned to the locomotor activity boxes for one re-habituation session (30 $\mathrm{min}$ ), followed by the aripiprazole challenge test one day later. On the challenge day, all rats were first injected with aripiprazole $3.0 \mathrm{mg} / \mathrm{kg}$ and then immediately placed in the locomotor activity boxes for $30 \mathrm{~min}$. At the end of the 30-minute period, they were taken out and injected with PCP $(3.20 \mathrm{mg} / \mathrm{kg}$ ) and placed back in the boxes for another $60 \mathrm{~min}$.

Phase 3: quinpirole-induced hyperlocomotion test. Two days after the aripiprazole challenge test in CAR, all rats were first habituated to the locomotor activity apparatus for two days (30 min/day), with the second day preceded by saline injections prior to habituation. One day later, they were injected with quinpirole $1.0 \mathrm{mg} /$ $\mathrm{kg}, \mathrm{sc}$ ) and immediately placed in the test apparatus for $120 \mathrm{~min}$. Locomotor activity (number of photobeam breaks) was measured in 10-minute blocks throughout the entire 120-minute test period.

\section{Statistical analysis}

All data were expressed as mean + standard error of the mean (SEM). Data from the five drug test sessions (e.g. avoidance response and PCP-induced hyperlocomotion) were analyzed using a factorial repeated measures analysis of variance (ANOVA) with the between-subjects factor being drug group and the withinsubjects factor being test session, followed by posthoc least significant difference (LSD) tests. Differences between groups on the specific drug test days, on the habituation day and on the challenge tests were analyzed using one-way ANOVAs, followed by post-hoc LSD tests. Differences between groups on the specific drug test days and on the challenge tests were analyzed using one-way ANOVAs, followed by post-hoc LSD tests. For all analyses, $p \leq 0.05$ was considered statistically significant and all data were analyzed using SPSS version 22.

\section{Results}

\section{Experiment 1: Effect of repeated aripiprazole treatment on avoidance response}

Phase 1: Five days of repeated aripiprazole testing. Figure 2(a) shows the mean number of avoidance responses made by rats in the four groups on the last training (predrug) day and five drug test days. There was no group difference on the last training day (predrug) $(F(3,32)=0.141, p=0.935)$. Throughout the five drug test days, aripiprazole increased its suppression of avoidance response progressively but not dose-dependently. Repeated measures ANOVA revealed a main effect of group $(F(3,32)=159.834, p<0.001)$, day $(F(4,128)=13.539, p<0.001)$, and a significant group $\times$ day interaction $(F(12,128)=2.797, p=0.002)$. Post-hoc LSD tests show that all three ARI groups made significantly fewer avoidance responses than the VEH group (all 

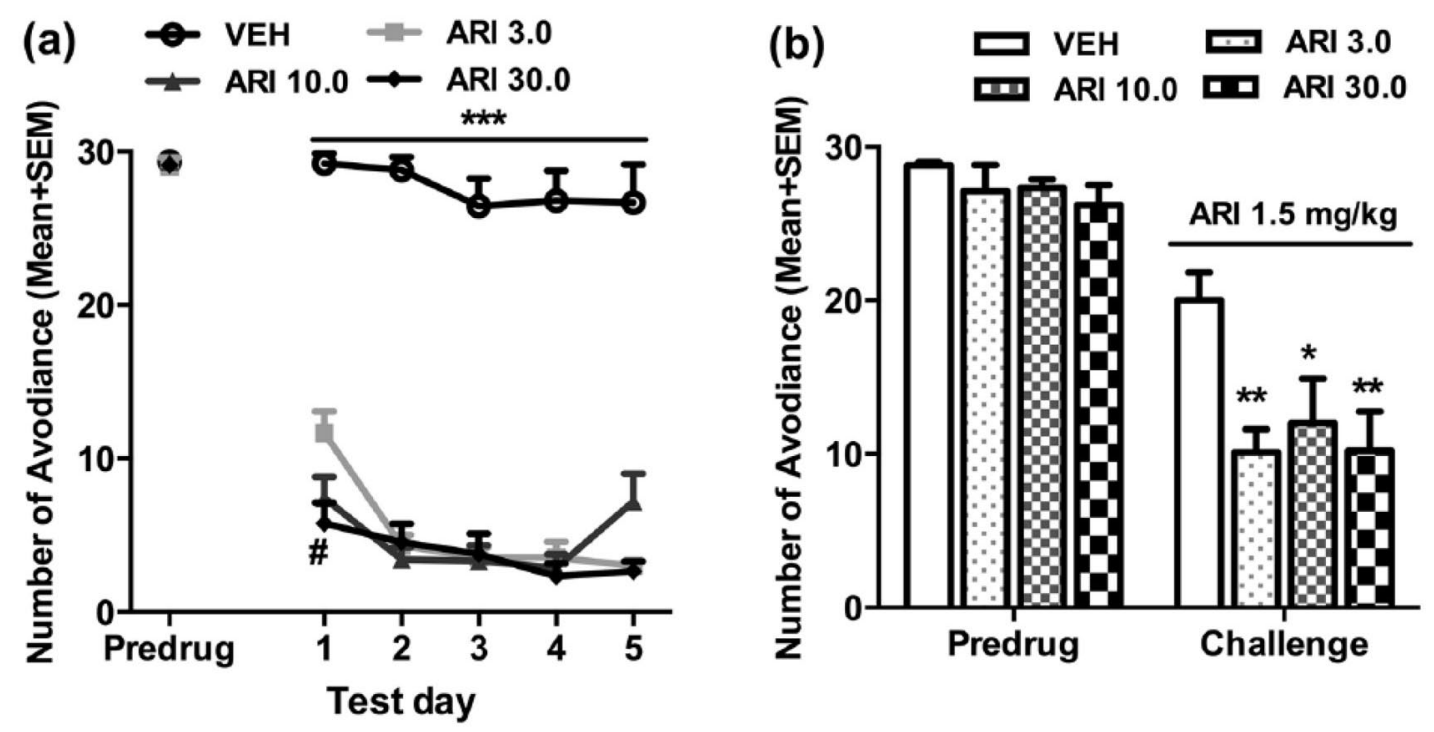

Figure 2. Repeated aripiprazole treatment increased avoidance response disruption and sensitivity to aripiprazole re-exposure. Number of avoidance responses made by the rats from the three aripiprazole treatment groups (ARI 3.0, 10.0, and 30.0 mg/kg) and the vehicle group (VEH) on the last training (predrug) day and throughout the five drug test days (a), and on the aripiprazole (1.5 mg/kg) challenge test (b) are expressed as mean + standard error of the mean (SEM). ${ }^{*} p<0.05,{ }^{* *} p<0.01,{ }^{* * *} p<0.001$ relative to VEH group; $\# p<0.05$ for comparison to the ARI 3.0 group.

ps<0.001), but the three ARI groups did not differ from each other (all $p s>0.283$ ). One-way ANOVA on each test day revealed that all three ARI groups had significantly lower avoidance than the VEH group on all five days (all $p s<0.001$ ). Additionally, on day 1 , the ARI 30.0 group showed lower avoidance than the ARI 3.0 group $(p=0.002)$.

Phase 2: Aripiprazole challenge test. Figure 2(b) shows the number of avoidance responses on the retraining day (predrug day) and the aripiprazole challenge day. No significant group difference was detected on the predrug day $(F(3,32)=0.913, p=0.446)$. However, on the challenge day when all rats were injected with aripiprazole $1.5 \mathrm{mg} / \mathrm{kg}$, the three ARI (3.0, 10.0, and $30.0 \mathrm{mg} / \mathrm{kg}$ ) groups made fewer avoidance responses than the VEH group, indicating a sensitization effect. One-way ANOVA confirmed a main effect of group $(F(3,32)=4.276, p=0.012)$. Post-hoc LSD tests showed that all three ARI groups were significantly different from the VEH group ( $p=0.004,0.018$, and 0.005 for ARI 3.0, 10.0, and 30.0), although the three ARI groups did not differ significantly from each other (all $p \mathrm{~s}>0.559$ ).

Phase 3: Quinpirole-induced hyperlocomotion test. To test whether the $D_{2 / 3}$ receptor system was involved in aripiprazole sensitization, we tested quinpirole-induced locomotor activity in rats that were pretreated with ARI (three ARI groups) or vehicle. This test was conducted two days after the aripiprazole challenge test. As shown in Figure 3(a), quinpirole at $1.0 \mathrm{mg} / \mathrm{kg}$ increased motor activity during the 120-minute test period, with a higher motor activity found in the aripiprazole pretreated rats than the VEH pretreated ones. Repeated measures ANOVA revealed a significant main effect of group $(F(3,32)=5.134, p=0.005)$, timeblock $(F(11,352)=127.823, p<0.001)$, and a significant group $\times$ block interaction $(F(33,352)=3.169, p<0.001)$. Post-hoc LSD tests show that the ARI 10.0 and ARI 30.0 groups made significantly more activity than the VEH ( $p s<0.020)$ and ARI 3.0 groups $(p s<0.008)$; but the ARI 3.0 and VEH groups did not differ significantly from each other $(p=0.659)$. One-way ANOVA with post-hoc LSD tests revealed that the ARI 10.0 group on the last six 10 -minute blocks (70-120 min, all ps<0.037), and ARI 30.0 group on 2nd9th 10-minute blocks (20-90 min, all $p s<0.039)$ had significantly higher motor activity than the VEH group, while ARI 10.0 group on the last eight $10-\mathrm{min}$ blocks $(50-120 \mathrm{~min}$, all $p s<0.040)$ and ARI 30.0 group on 2 nd-9th 10-minute blocks (20-90 min, all $p s<0.016)$ had significantly higher motor activity than the ARI 3.0 group.

Similarly, there was also a main effect of group on the total motor activity in $120 \mathrm{~min}$ (Figure $3(\mathrm{~b}), F(3,32)=5.134, p=0.005)$ ). Post-hoc LSD tests showed that the ARI 10.0 and ARI 30.0 groups had significantly higher motor activity than the VEH group ( $p=0.019$ and 0.014 , respectively), and the ARI 3.0 group $(p=0.007$ and 0.005 , respectively). These findings suggest that repeated aripiprazole treatment induced an increase in $D_{2 / 3}$ receptor- mediated function dose-dependently, which may serve as one mechanism for aripiprazole sensitization in CAR.

\section{Experiment 2: Effect of repeated aripiprazole treatment on PCP-induced hyperlocomotion} Phase 1: Five days of repeated aripiprazole testing. Figure 4(a) shows the mean motor activity of the four groups of rats during the 30-min period before PCP or vehicle injection throughout the 5 days of drug testing. Repeated measures ANOVA revealed a main effect of group $(F(4,27)=18.538, p<0.001)$, day $(F(4,108)=47.761, p<0.001)$, and significant group $\times$ day interaction $(F(16,108)=6.973, p<0.001)$. Post-hoc LSD tests revealed that the four PCP-treated groups had significantly lower motor activity than the $\mathrm{VEH}+\mathrm{VEH}$ group (all $p s \leq 0.001$ ), mainly on Days $2-5$. 

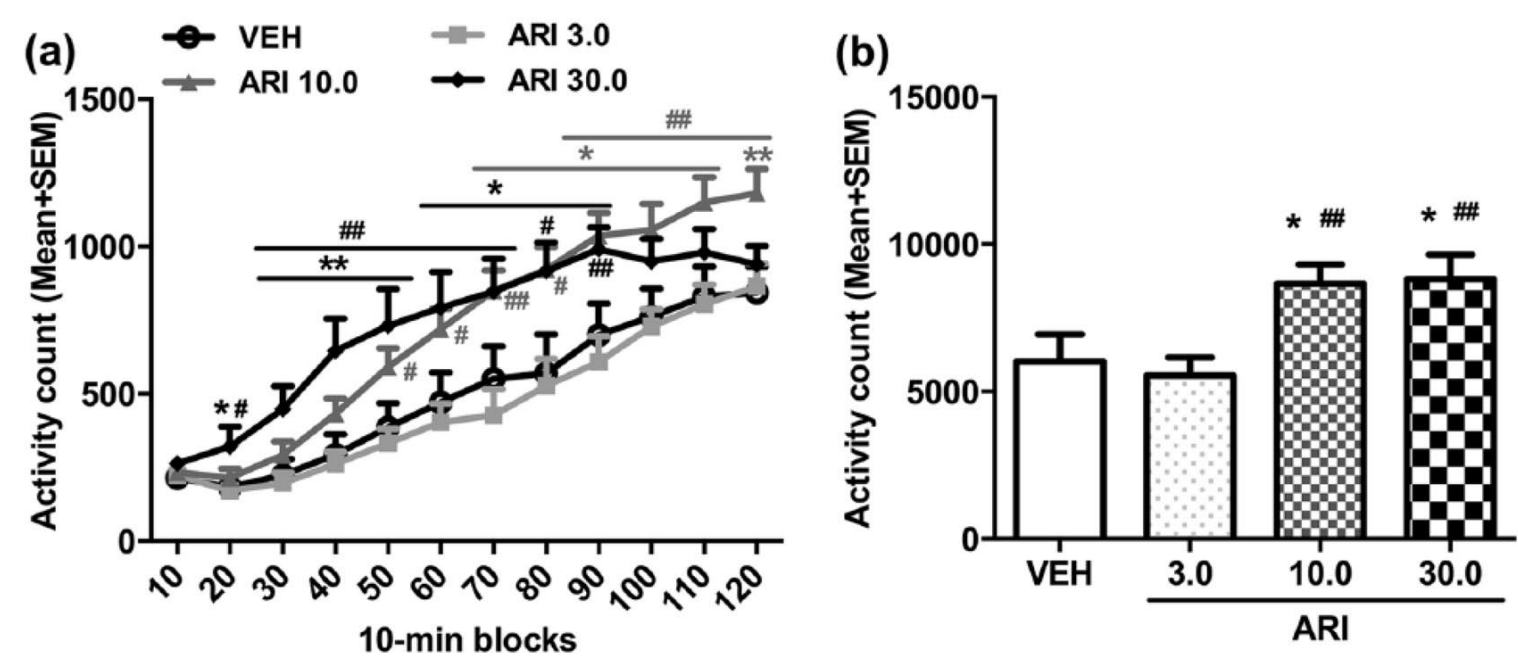

Figure 3. Quinpirole-induced locomotor activity in 12 10-minute blocks (a) or in $120 \mathrm{~min}$ (b) in the quinpirole-induced hyperlocomotion test. The test was conducted two days after the last aripiprazole (ARI) challenge test. All rats were injected with quinpirole (1.0 mg/kg, subcutaneously (sc)) and then measured for motor activity for $120 \mathrm{~min}$. All data are expressed as mean + standard error of the mean (SEM) in 12 10-minute blocks. ${ }^{*} p<0.05$, ${ }^{* *} p<0.01$ for comparison to the vehicle (VEH) group; $\# p<0.05$, \#\#p<0.01 for comparison to the ARI 3.0 group.
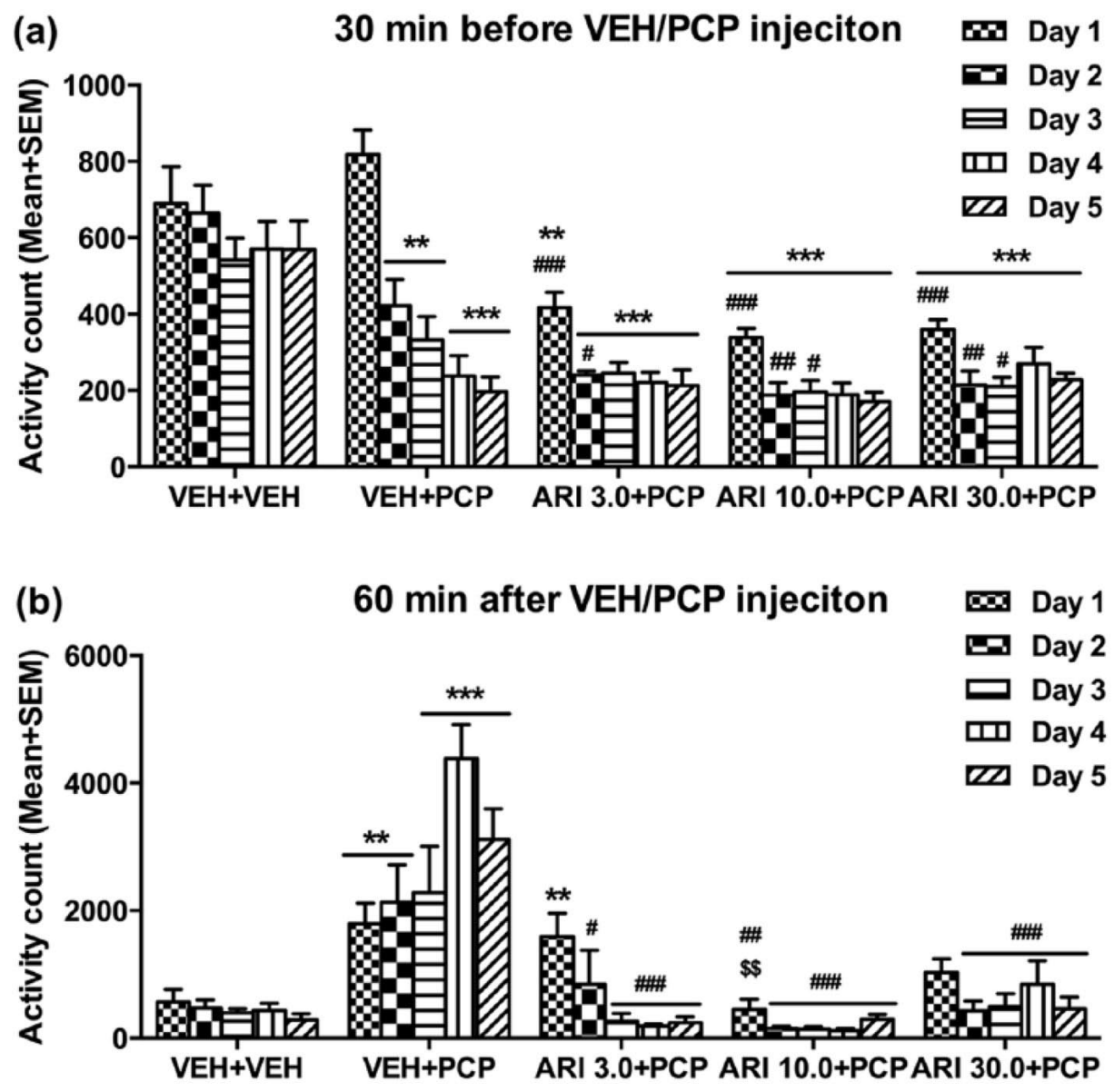

Figure 4. Effect of repeated aripiprazole (ARI 3.0, 10.0 and $30.0 \mathrm{mg} / \mathrm{kg}$ ) treatment on phencyclidine (PCP)-induced hyperlocomotion across the five test days ( $n=6-7 /$ group). Locomotor activity in the 30 min before vehicle(VEH) or PCP injection (a) and 60 min after PCP injection (b) are expressed as mean + standard error of the mean (SEM) for each group. ${ }^{* *} p<0.01,{ }^{* *} p<0.001$ relative to the VEH+VEH group; $\# p<0.05, \# \# p<0.01, \# \# \# p<0.001$ relative to the $\mathrm{VEH}+\mathrm{PCP}$ group. 

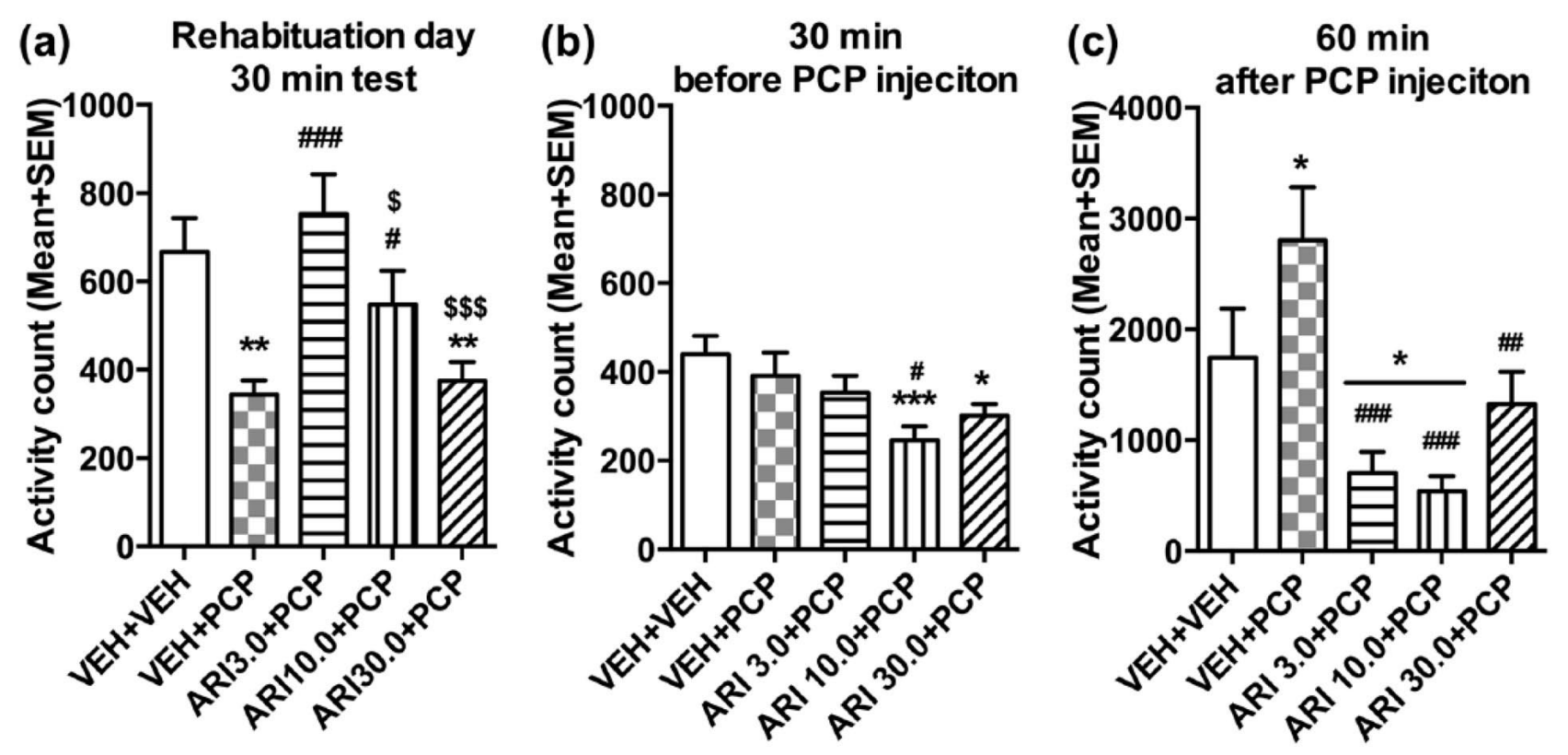

Figure 5. Locomotor activity during the 30-minute test period on the rehabituation day (a), 30-minute test period before phencyclidine (PCP) injection (b) and the 60-minute test period after PCP injection (c) on the aripiprazole (ARI) challenge test day. ${ }^{*} p<0.05,{ }^{* *} p<0.01,{ }^{* * *} p<0.001$ relative to the

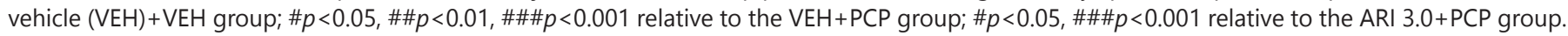

Figure $4(\mathrm{~b})$ shows the mean motor activity of the five groups of rats during the 60-minute period after PCP or vehicle injection throughout the five days of drug testing. Two-way repeated measures ANOVA revealed a significant main effect of group $(F(4,27)=20.641, p<0.001)$, day $(F(4,108)=4.214, p=0.003)$, and a significant group $\times$ day interaction $(F(16,108)=6.786, p<0.001)$. Post-hoc LSD tests revealed that the three ARI+PCP (ARI 3.0, 10.0 , and $30.0+P C P$ ) groups exhibited significantly lower motor activity compared to the VEH+PCP group (all $p s<0.001$ ). The $V E H+P C P$ group had significantly higher motor activity than the VEH+VEH group $(p<0.001)$, indicating a strong psychomotor activation effect of this dose of PCP. One-way ANOVA on each test day revealed that the all three ARI (3.0, 10.0 and 30.0+PCP) groups had significantly lower activity than the VEH+PCP group on Days 2-5 (all $p s<0.016$ ). In addition, the ARI 10.0+PCP group also had significantly lower motor activity than VEH+PCP group $(p=0.002)$ and ARI 3.0+PCP group $(p=0.004)$ on Day 1.

Phase 2: Re-habituation and aripiprazole challenge test. On the re-habituation day, rats previously treated with VEH+PCP or ARI 30.0+PCP had lower motor activity than other groups (Figure 5(a)). One-way ANOVA showed a significant effect of group $(F(4,27)=6.870, p=0.001)$. Post-hoc test showed that the two ARI (3.0 and $10.0 \mathrm{mg} / \mathrm{kg}$ ) groups (all $p s<0.041$ ) and $\mathrm{VEH}+\mathrm{VEH}$ group $(p=0.003)$ had significantly higher motor activity than the $\mathrm{VEH}+\mathrm{PCP}$ group, and the ARI 3.0+PCP group had higher motor activity than the ARI 10.0+PCP $(p=0.039)$ and ARI $30.0+P C P$ groups $(p<0.001)$. In addition, the ARI $30.0+P C P$ group showed significantly lower motor activity relative to the $\mathrm{VEH}+\mathrm{VEH}$ group $(p=0.004)$. These results suggest that concurrent 3.0 and 10.0 $\mathrm{mg} / \mathrm{kg}$ ARI treatment with PCP prevented the PCP-withdrawalinduced decrease in spontaneous motor activity.
On the ARI sensitization challenge test, in the first $30 \mathrm{~min}$ (Figure 5(b)), the three ARI groups had lower motor activity than the vehicle group. One-way ANOVA revealed a main effect of $\operatorname{group}(F(4,27)=4.024, p=0.011)$. The ARI 10.0+PCP group had significantly lower motor activity than the VEH+PCP group $(p=0.011)$, and both ARI 10.0+PCP and ARI 30.0+PCP groups had significantly lower motor activity than the VEH+VEH group ( $p=0.001,0.015$, respectively). In the 60 -minute test period after PCP injection (Figure 5(c)), one-way ANOVA revealed a main effect of group $(F(4,27)=7.678, p<0.001)$. Post hoc comparisons revealed that the all three ARI (ARI 3.0, 10.0 and 30.0+PCP) groups had significantly lower motor activity than the VEH+PCP group (all $p s \leq 0.003$ ), indicating a ARI sensitization effect.

Collectively, results from this experiment provided further evidence of aripiprazole sensitization. Similar to aripiprazole sensitization observed in the conditioned avoidance test (experiment 1), this effect was manifested as an enhanced inhibition of PCPinduced hyperlocomotion (an index of antipsychotic activity) in the ARI treated animals.

Phase 3: Quinpirole-induced hyperlocomotion test. To test whether the $D_{2 / 3}$ receptor system was involved in aripiprazole sensitization, we tested quinpirole-induced locomotor activity in rats tested in the PCP model. This test was conducted two days after the ARI challenge test in PCP model. As shown in Figure $6(\mathrm{a})$, quinpirole at $1.0 \mathrm{mg} / \mathrm{kg}$ increased motor activity during the 120-minute test period, with a higher motor activity found in the ARI $30.0+P C P$ pretreated rats than the VEH+PCP pretreated ones. Repeated measures ANOVA revealed a significant main effect of group $(F(4,27)=3.794, p=0.014)$, time-block $(F(11,297)=43.61, p<0.001)$, and a significant group $\times$ block interaction $(F(44,297)=1.926, p=0.001)$. Post-hoc LSD tests show that 

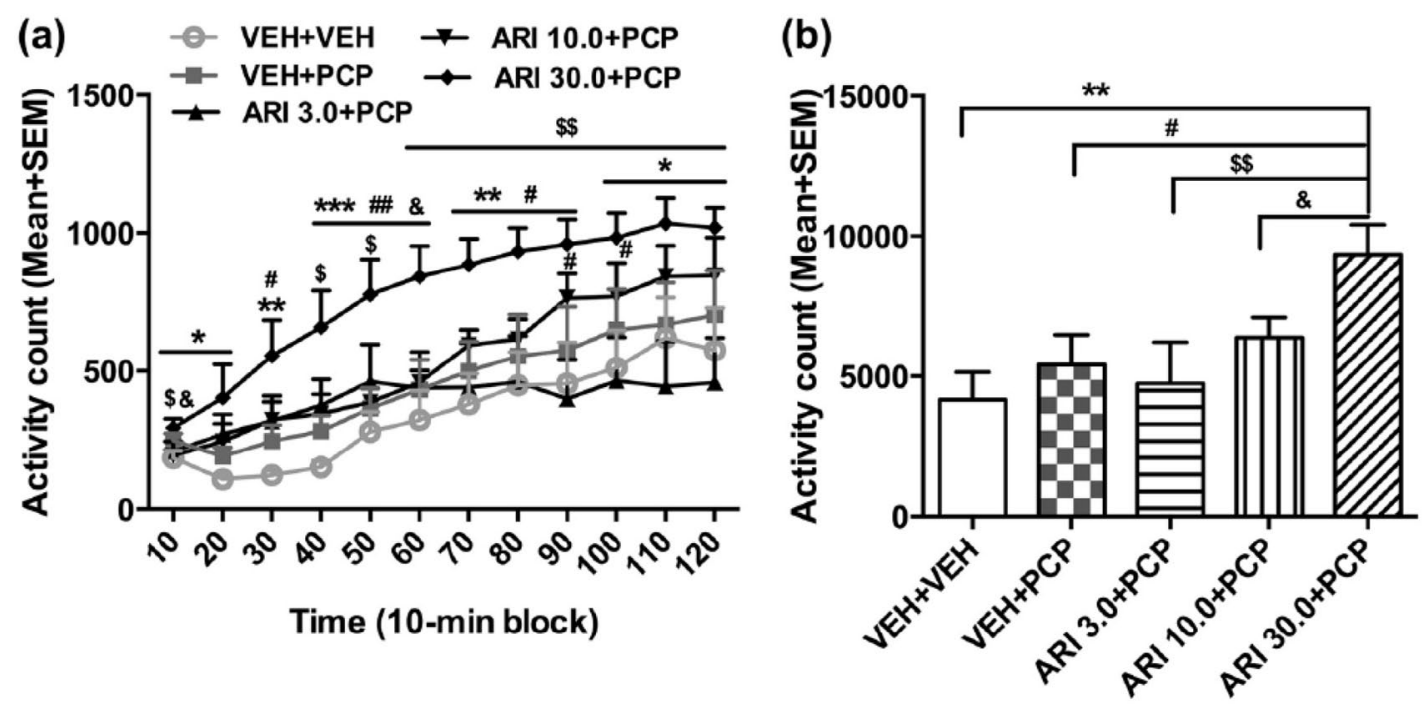

Figure 6. Quinpirole-induced locomotor activity in 12 10-min blocks (a) or in $120 \mathrm{~min}$ (b) in the quinpirole-induced hyperlocomotion test. The test was conducted two days after the last aripiprazole (ARI) challenge test. All rats were injected with quinpirole (1.0 mg/kg, subcutaneously (sc)) and then measured for motor activity for 120 min. All data are expressed as mean + standard error of the mean (SEM) in 12 10-minute blocks. PCP: phencyclidine; VEH: vehicle. ${ }^{*} p<0.05,{ }^{* *} p<0.01,{ }^{* * *} p<0.001$ for comparison to the VEH+VEH group; $\# p<0.05, \# \# p<0.01$ for comparison to the VEH+PCP group; $\$ p<0.05$, $\$ p<0.01$ for comparison to the ARI 3.0+PCP group; $\& p=0.05$ for comparison to the ARI 10.0+PCP group.

the ARI 30.0+PCP group was significantly more active than the $\mathrm{VEH}+\mathrm{VEH}$ group $(p=0.002)$, the VEH+PCP group $(p=0.014)$, and the ARI 3.0+PCP group ( $p=0.005)$; but the ARI 3.0+PCP and ARI $10.0+P C P$ groups did not differ significantly from the VEH+PCP group (all $p s>0.524$ ). One-way ANOVA with post-hoc LSD tests revealed that the ARI 30.0+PCP group had significantly higher motor activity than the VEH+PCP group on the 3rd-9th 10-minute blocks (30-90 min, all $p s<0.039), \mathrm{VEH}+\mathrm{VEH}$ group on all 12 10-minute blocks (all $p s<0.035$ ), and ARI 3.0+PCP group at 10, 40-120 min points ( $p s<0.043$ ), and ARI 10.0+PCP group at the 10 and 60 min points ( $p s<0.015$ ), while the ARI 10.0 group had significantly higher motor activity than the ARI 3.0 group at the 90 and 110 min points (all ps<0.049).

Similarly, the group difference on the total motor activity in 120 min was also significant (Figure $6(b), F(4,27)=3.794, p=0.014$ ). Post-hoc LSD tests showed that the ARI 30.0+PCP group was significantly different from the $\mathrm{VEH}+\mathrm{VEH}$ group $(p=0.002)$, VEH+PCP group $(p=0.014), \operatorname{ARI} 3.0+\operatorname{PCP}$ group $(p=0.005)$, and ARI 10.0+PCP group $(p=0.050)$. These data are consistent with those reported in experiment 1 and suggest that repeated aripiprazole treatment induced an increase in $D_{2 / 3}$ receptor-mediated function dose-dependently, a change that may partially underlie aripiprazole sensitization.

\section{Discussion}

Aripiprazole is an atypical antipsychotic drug with mechanisms of action distinctive from the more widely used atypicals, such as clozapine, risperidone, olanzapine, and quetiapine. Aripiprazole shows high affinity for dopamine $D_{2}$ receptors but as a partial agonist rather than a full antagonist at these receptors ( $\mathrm{Ai}-$ hara et al., 2004; Burris et al., 2002; Kikuchi et al., 1995; Lawler et al., 1999; Shapiro et al., 2003). As a result, it acts as a $D_{2}$ receptor agonist at receptor sites where dopaminergic transmis- sion is significantly decreased while acting as an antagonist at other dopaminergic sites with normal or increased transmission, functioning as a dopamine activity stabilizer. In addition to the action of aripiprazole on dopamine receptors, this drug shows partial agonism at 5- $\mathrm{HT}_{1 \mathrm{~A}}$ receptors and antagonism at 5- $\mathrm{HT}_{2 \mathrm{~A}}$ receptors (Jordan et al., 2002; Kikuchi et al., 1995). In the present study, we demonstrated that repeated aripiprazole treatment for five days caused an augmentation of its disruption of avoidance responding and inhibition of PCP-induced hyperlocomotion in a dose-dependent fashion. This effect was observed in both the induction phase and expression phase using two measures of sensitization (withinsubjects and between-subjects comparisons). Therefore, despite its novel mechanisms, aripiprazole induced a sensitized behavioral effect similar to those of other atypicals (e.g. olanzapine, risperidone, and asenapine). Furthermore, repeated aripiprazole treatment also increased sensitivity to quinpirole challenge, indicating an upregulation of $D_{2 / 3}$-mediated neurotransmission. These findings reveal that aripiprazole shares a similar feature of sensitization with haloperidol, asenapine, olanzapine, and risperidone in behavioral tests of antipsychotic activity, and that this long-term effect is likely related to plastic changes in $\mathrm{D}_{2 / 3}$-receptors and other receptors that aripiprazole targets.

Previous work has shown that acute aripiprazole treatment at 10 and $30 \mathrm{mg} / \mathrm{kg}$ significantly suppresses conditioned avoidance response in rats (Hertel et al., 2005; Natesan et al., 2006). The present study extended this finding to show that repeated aripiprazole treatment intensifies this suppression over time and this intensification was long-lasting and could be detected in a later drug challenge test, as rats previously treated with aripiprazole showed significantly lower avoidance than the drug-naive rats. Similarly in the PCP-induced hyperlocomotion test, our finding on the acute aripiprazole effect is consistent with a previous report showing that aripiprazole reduces PCP-induced in- 
crease in locomotor activity at $1-30 \mathrm{mg} / \mathrm{kg}$ (Nordquist et al., 2008). Again, the novel finding is on the sensitization effect of aripiprazole that manifested as the progressively enhanced suppression of PCP-induced hyperlocomotion during the induction phase (Figure $4(b)$ ), and an enhanced sensitivity to aripiprazole challenge in the expression phase (Figure 5(b) and (c)). To our knowledge, this is the first report on the repeated behavioral effects of aripiprazole in these two models. The fact that the same sensitization effect was found in two distinct behavioral assessments supports the generalizability of such an effect. Because aripiprazole at the doses used here induces approximately 65$85 \% \mathrm{D}_{2}$ occupancies in rodents (Natesan et al., 2006), a level which is commonly found in human volunteers treated with adequate doses of aripiprazole (Yokoi et al., 2002). Thus, it seems likely that the doses we used were sufficient and clinically relevant, and the sensitization effect of aripiprazole may reflect an intrinsic feature of this drug.

This intrinsic feature does not distinguish aripiprazole from other atypical antipsychotic drugs at least at the behavioral level since most other antipsychotic drugs, except for clozapine, also induce a sensitization effect in these two widely used behavioral tests (Feng et al., 2013; Li et al., 2012; Mead and Li, 2010; Qiao et al., 2013; Qin et al., 2013; Swalve and Li, 2012; Zhang and Li, 2012). Clozapine is the only drug that induces a tolerance effect in these tests (Feng et al., 2013; Li et al., 2010, 2012). On this front, it can be inferred that aripiprazole has a clinical profile similar to that of olanzapine, risperidone, and asenapine but different from that of clozapine. As a basic principle in psychopharmacology, the demonstration of aripiprazole sensitization further supports the notion that once an organism is exposed to an antipsychotic drug, this drug experience stays with it for a long period of time and may have a drug memory-like characteristic. Clinically, antipsychotic sensitization has been considered as a behavioral mechanism underlying the therapeutic effects of antipsychotic treatment (Kapur et al., 2006; Sun et al., 2009), as it matches with the early onset and progressive improvement pattern of antipsychotic response in patients (Agid et al., 2003). Thus, it can be said that the gradual improvement of psychotic symptoms over time is due to the drug-induced sensitization process that intensifies the behavioral effects of the drug. However, antipsychotic sensitization may also underlie the drug-induced extrapyramidal motor syndrome and tardive dyskinesia (Turrone et al., 2005), an idea also supported by the findings that acute or repeated administration of many antipsychotic drugs, including aripiprazole, causes an impairment of motor function or coordination (Barnes et al., 1990; Burda et al., 2011; Nordquist et al., 2008). At this point, the clinical significance of antipsychotic sensitization in general and aripiprazole sensitization in particular is still not clear. From this perspective, understanding the clinical significance of aripiprazole sensitization and associated neurobiological mechanisms may help enhance our understanding of the behavioral and neurobiological mechanisms of clinical antipsychotic response.

One interesting finding is that the VEH+PCP group had significantly lower spontaneous motor activity than the VEH+VEH group on the rehabituation day when all rats were placed in the test boxes drug-free for 30 min (Figure 5(a)), suggesting a PCP withdrawal-induced decrease in motor activity. This effect has not been reported before (Qin et al., 2013) and may reflect PCP withdrawal- induced anxiety or depression which is well known in the literature (Audet et al., 2007; Baird et al., 2008; Noda et al., 1995; Renoir et al., 2012; Spielewoy and Markou, 2003). Interestingly, concurrent ARI treatment at 3 and $10 \mathrm{mg} / \mathrm{kg}$ alleviated this effect. Similar findings have been reported with clozapine and risperidone (Grayson et al., 2007; Qiao et al., 2001). ARI at $30 \mathrm{mg} / \mathrm{kg}$ did not exhibit this effect, possibly due to the qualitative and quantitative differences in brain plasticity between this dose of ARI and other doses. For example, Peselmann et al. (2013) found that the gene expression of gamma-aminobutyric acid (GABA) transmembrane transporters Slc6a1 (Gat1) and Slc6a11 (Gat3) in the hippocampus, caudate nucleus and putamen, and cerebral cortex were increased by a lower dose (10 $\mathrm{mg} / \mathrm{kg}$ ) rather than a higher dose $(40 \mathrm{mg} / \mathrm{kg}$ ) of ARI (Peselmann et al., 2013), and Zocchi et al. (2005) demonstrated that aripiprazole at lower dose $(0.3 \mathrm{mg} / \mathrm{kg}$ ) but not higher doses (3 and $30 \mathrm{mg} / \mathrm{kg}$ ) produced a significant increase in extracellular levels of dopamine in the mouse frontal cortex. Future studies should attempt to replicate this effect and the effect of PCP withdrawalinduced decrease in motor activity to further understand their neurobiological mechanisms.

At the receptor level, aripiprazole-induced sensitization seems partially to be accompanied by drug-induced functional changes in dopamine $D_{2 / 3}$ receptors. This was revealed in the quinpirole-induced hyperlocomotion test, a validated behavioral assay of $\mathrm{D}_{2}$-mediated neurotransmission. Aripiprazole-pretreated rats had significantly higher motor activity than the corresponding vehicle rats under the quinpirole challenge. Seeman (2008) also found that one week of aripiprazole treatment significantly increased the ratio of $D_{2}$ High receptors in the striatum of adult rats, an effect that is often associated with dopamine supersensitivity (Seeman et al., 2005). Our current finding is similar to our previously reported risperidone-induced sensitization, as risperidonepretreated rats were also more active than the corresponding vehicle rats when challenged with quinpirole (Gao and $L i$, 2013). In addition to dopamine $D_{2 / 3}$ receptors, serotonin $5-\mathrm{HT}_{2 \mathrm{~A} / 2 \mathrm{C}}$ receptor systems may also play important roles in antipsychotic sensitization. Recently, we showed that pretreatment of quinpirole or 2,5-dimethoxy-4-iodo-amphetamine ( $\mathrm{DOI}$, a selective $5-\mathrm{HT}_{2 \mathrm{~A} / 2 \mathrm{C}}$ agonist) attenuated the magnitude of olanzapine sensitization effect (Li et al., 2010). In the case of aripiprazole sensitization, the neuroreceptor mechanisms may involve other receptors in addition to dopamine $\mathrm{D}_{2 / 3}$. First, aripiprazole has additional high affinity for several $5-\mathrm{HT}$ receptors (e.g. $5-\mathrm{HT}_{1 \mathrm{~A}^{\prime}}$ $5-\mathrm{HT}_{2 \mathrm{~A}^{\prime}} 5-\mathrm{HT}_{2 \mathrm{~B}}$ and $\left.5-\mathrm{HT}_{7}\right), \alpha_{1}$-adrenergic and $\mathrm{H}_{1}$-histamine receptors, and functions as an inverse agonist at $5-\mathrm{HT}_{2 \mathrm{~B}}$ receptors and a partial agonist at $5-\mathrm{HT}_{2 \mathrm{~A}^{\prime}} 5-\mathrm{HT}_{2 \mathrm{C}^{\prime}} \mathrm{D}_{3^{\prime}}$ and $\mathrm{D}_{4}$ receptors (Shapiro et al., 2003). It is conceivable that five days of repeated aripiprazole treatment could also have altered the functions of these receptors in addition to alteration of $\mathrm{D}_{2}$ receptors. Second, Inoue et al. (1997) showed that repeated administration of aripiprazole at $12-100 \mathrm{mg} / \mathrm{kg}$ dose range for three weeks did not induce any up-regulation of dopamine $\mathrm{D}_{2}$ mRNA expression in the striatum. Tadokoro et al. (2012) reported that aripiprazole at $1.5 \mathrm{mg} / \mathrm{kg} /$ day via minipump for 14 days does not cause an in- 
crease in $D_{2}$ binding sites and dopamine supersensitivity in adult rats. These findings suggest that $D_{2}$ receptor-mediated neurotransmission might not be critical in support of aripiprazole's long-term effect. We speculate that the observed enhanced sensitivity to quinpirole challenge in aripiprazole-treated rats may reflect drug-induced changes on other receptors (e.g. 5- $\mathrm{HT}_{1 \mathrm{~A}^{\prime}}$ $5-\mathrm{HT}_{2 \mathrm{~A}^{\prime}} 5-\mathrm{HT}_{2 \mathrm{~B}}$ ) in other parts of the brain (e.g. medial prefrontal cortex). Finally, aripiprazole at $3.0 \mathrm{mg} / \mathrm{kg}$ did not induce any changes in quinpirole-induced hyperlocomotion in motor activity in both experiments (Figure 3(b) and Figure 6(b)): however, it clearly induced a sensitization effect (Figure 2(b) and Figure $5(\mathrm{c})$ ), suggesting that dopamine $\mathrm{D}_{2 / 3}$ might be just one of many mechanisms involved in aripiprazole sensitization.

In summary, aripiprazole is a novel antipsychotic drug which shares a similar repeated behavioral profile with most antipsychotic drugs (e.g. olanzapine, risperidone, asenapine) on the basis of the findings that its repeated treatment caused a sensitization effect in both the induction and expression phases of the CAR and PCPinduced hyperlocomotion tests. One potential receptor mechanism responsible for its sensitization effect is the functional changes in dopamine $\mathrm{D}_{2 / 3}$ system. Future work should explore other molecular mechanisms and identify the relevant neurochemical systems and various forms of neuroplasticity (Allen et al., 2011; Konradi and Heckers, 2001; Lieberman et al., 2008; Meltzer et al., 1989).

Acknowledgments - This study was funded by the National Institute of Mental Health grant (R01MH085635) to Ming Li. The authors declared no potential conflicts of interest with respect to the research, authorship, and/or publication of this article.

\section{References}

Agid O, Kapur S, Arenovich T, et al. (2003) Delayed-onset hypothesis of antipsychotic action: A hypothesis tested and rejected. Arch Gen Psychiatry 60: 1228-1235.

Aihara K, Shimada J, Miwa T, et al. (2004) The novel antipsychotic aripiprazole is a partial agonist at short and long isoforms of D2 receptors linked to the regulation of adenylyl cyclase activity and prolactin release. Brain Res 1003: 9-17.

Allen JA, Yost JM, Setola V, et al. (2011) Discovery of betaarrestin-biased dopamine $\mathrm{D}_{2}$ ligands for probing signal transduction pathways essential for antipsychotic efficacy. Proc Natl Acad Sci U S A 108: 18488-18493.

Audet MC, Goulet S and Dore FY (2007) Enhanced anxiety follows withdrawal from subchronic exposure to phencyclidine in rats. Behav Brain Res 176: 358-361.

Baird JP, Turgeon S, Wallman A, et al. (2008) Behavioral processes mediating phencyclidine-induced decreases in voluntary sucrose consumption. Pharmacol Biochem Behav 88: 272-279.

Barnes DE, Robinson B, Csernansky JG, et al. (1990) Sensitization versus tolerance to haloperidol-induced catalepsy: Multiple determinants. Pharmacol Biochem Behav 36: 883-887.

Bortolozzi A, Diaz-Mataix L, Toth M, et al. (2007) In vivo actions of aripiprazole on serotonergic and dopaminergic systems in rodent brain. Psychopharmacology (Berl) 191: 745-758.

Burda K, Czubak A, Kus K, et al. (2011) Influence of aripiprazole on the antidepressant, anxiolytic and cognitive functions of rats. Pharmacol Rep 63: 898-907.
Burris KD, Molski TF, Xu C, et al. (2002) Aripiprazole, a novel antipsychotic, is a high-affinity partial agonist at human dopamine $D_{2}$ receptors. J Pharmacol Exp Ther 302: 381-389.

Carli M, Calcagno E, Mainolfi P, et al. (2011) Effects of aripiprazole, olanzapine, and haloperidol in a model of cognitive deficit of schizophrenia in rats: Relationship with glutamate release in the medial prefrontal cortex. Psychopharmacology (Berl) 214: 639-652.

Cosi C, Carilla-Durand E, Assie MB, et al. (2006) Partial agonist properties of the antipsychotics ssr181507, aripiprazole and bifeprunox at dopamine D2 receptors: $\mathrm{G}$ protein activation and prolactin release. Eur J Pharmacol 535: 135-144.

Feng M, Sui N and Li M (2012) Avoidance disruptive effect of clozapine and olanzapine is potentiated by increasing the test trials: Further test of the motivational salience hypothesis. Pharmacol Biochem Behav 103: 467-473.

Feng M, Sui N and Li M (2013) Environmental and behavioral controls of the expression of clozapine tolerance: Evidence from a novel acrossmodel transfer paradigm. Behav Brain Res 238: 178-187.

Gao J and Li M (2013) Time-dependence of risperidone and asenapine sensitization and associated D2 receptor mechanism. Behav Brain Res 257: 286-294.

Gleason SD and Shannon HE (1997) Blockade of phencyclidine-induced hyperlocomotion by olanzapine, clozapine and serotonin receptor subtype selective antagonists in mice. Psychopharmacology (Berl) 129: 79-84.

Grayson B, Idris NF and Neill JC (2007) Atypical antipsychotics attenuate a sub-chronic PCP-induced cognitive deficit in the novel object recognition task in the rat. Behav Brain Res 184: 31-38.

Hertel P, Olsen CK, Didriksen M, et al. (2005) Bifeprunox: A new and different antipsychotic. Schizophr Bull 31: 301.

Hirose T, Uwahodo Y, Yamada S, et al. (2004) Mechanism of action of aripiprazole predicts clinical efficacy and a favourable side-effect profile. J Psychopharmacol 18: 375-383.

Inoue A, Miki S, Seto M, et al. (1997) Aripiprazole, a novel antipsychotic drug, inhibits quinpirole-evoked gtpase activity but does not up-regulate dopamine D2 receptor following repeated treatment in the rat striatum. Eur J Pharmacol 321: 105-111.

Jordan S, Koprivica V, Chen R, et al. (2002) The antipsychotic aripiprazole is a potent, partial agonist at the human $5-\mathrm{Ht} 1$ a receptor. Eur J Pharmacol 441: 137-140.

Kalinichev M, Robbins MJ, Hartfield EM, et al. (2008) Comparison between intraperitoneal and subcutaneous phencyclidine administration in Sprague-Dawley rats: A locomotor activity and gene induction study. Prog Neuropsychopharmacol Biol Psychiatry 32: 414-422.

Kapur S, Agid O, Mizrahi R, et al. (2006) How antipsychotics work-from receptors to reality. NeuroRx 3: 10-21.

Kikuchi T, Tottori K, Uwahodo Y, et al. (1995) 7-(4-[4-(2,3-dichlorophenyl)1-piperazinyl]butyloxy)-3,4-dihydro-2(1h)-qui nolinone (OPC-14597), a new putative antipsychotic drug with both presynaptic dopamine autoreceptor agonistic activity and postsynaptic $D_{2}$ receptor antagonistic activity. J Pharmacol Exp Ther 274: 329-336.

Koller W, Herbster G, Anderson D, et al. (1987) Quinpirole hydrochloride, a potential anti-Parkinsonism drug. Neuropharmacology 26: 1031-1036.

Konradi C and Heckers S (2001) Antipsychotic drugs and neuroplasticity: Insights into the treatment and neurobiology of schizophrenia. Biol Psychiatry 50: 729-742.

Lawler CP, Prioleau C, Lewis MM, et al. (1999) Interactions of the novel antipsychotic aripiprazole (Opc-14597) with dopamine and serotonin receptor Subtypes. Neuropsychopharmacology 20: 612-627.

Li M, Budin R, Fleming AS, et al. (2005) Effects of novel antipsychotics, amisulpiride and aripiprazole, on maternal behavior in rats. Psychopharmacology (Berl) 181: 600-610. 
Li M, Sun T and Mead A (2012) Clozapine, but not olanzapine, disrupts conditioned avoidance response in rats by antagonizing $5-\mathrm{Ht}(2 \mathrm{a} / 2 \mathrm{c})$ receptors. J Neural Transm 119: 497-505.

Li M, Sun T, Zhang C, et al. (2010) Distinct neural mechanisms underlying acute and repeated administration of antipsychotic drugs in rat avoidance conditioning. Psychopharmacology (Berl) 212: 45-57.

Li Z, Ichikawa J, Dai J, et al. (2004) Aripiprazole, a novel antipsychotic drug, preferentially increases dopamine release in the prefrontal cortex and hippocampus in rat brain. Eur J Pharmacol 493: 75-83.

Lieberman JA, Bymaster FP, Meltzer HY, et al. (2008) Antipsychotic drugs: Comparison in animal models of efficacy, neurotransmitter regulation, and neuroprotection. Pharmacol Rev 60: 358-403.

Luque-Rojas MJ, Galeano P, Suarez J, et al. (2013) Hyperactivity induced by the dopamine $D_{2} / D_{3}$ receptor agonist quinpirole is attenuated by inhibitors of endocannabinoid degradation in mice. Int J Neuropsychopharmacol 16: 661-676.

Mamo D, Graff A, Mizrahi R, et al. (2007) Differential effects of aripiprazole on $\mathrm{D}(2), 5-\mathrm{Ht}(2)$, and $5-\mathrm{Ht}(1 \mathrm{a})$ receptor occupancy in patients with schizophrenia: A triple tracer pet Study. Am J Psychiatry 164: 1411-1417.

Mead A and Li M (2010) Avoidance-suppressing effect of antipsychotic drugs is progressively potentiated after repeated administration: An interoceptive drug state mechanism. J Psychopharmacol 24: 1045-1053.

Meltzer HY, Matsubara S and Lee JC (1989) The ratios of serotonin2 and dopamine2 affinities differentiate atypical and typical antipsychotic drugs. Psychopharmacol Bull 25: 390-392.

Nakamura S, Yue JL, Goshima Y, et al. (1994) Non-effective dose of exogenously applied L-dopa itself stereoselectively potentiates postsynaptic D2 receptor-mediated locomotor activities of conscious rats. Neurosci Lett 170: 22-26.

Natesan S, Reckless GE, Nobrega JN, et al. (2006) Dissociation between in vivo occupancy and functional antagonism of dopamine D2 receptors: Comparing aripiprazole to other antipsychotics in animal models. Neuropsychopharmacology 31: 1854-1863.

Noda Y, Yamada K, Furukawa H, et al. (1995) Enhancement of immobility in a forced swimming test by subacute or repeated treatment with phencyclidine: A new model of schizophrenia. Br J Pharmacol 116: 2531-2537.

Nordquist RE, Risterucci C, Moreau JL, et al. (2008) Effects of aripiprazole/opc-14597 on motor activity, pharmacological models of psychosis, and brain activity in rats. Neuropharmacology 54: 405-416.

Peselmann N, Schmitt A, Gebicke-Haerter PJ, et al. (2013) Aripiprazole differentially regulates the expression of gad67 and gamma-aminobutyric acid transporters in rat brain. Eur Arch Psychiatry Clin Neurosci 263: 285-297.

Prosser ES, Pruthi R and Csernansky JG (1989) Differences in the time course of dopaminergic supersensitivity following chronic administration of haloperidol, molindone, or sulpiride. Psychopharmacology (Berl) 99: 109-116.

Qiao H, Noda Y, Kamei H, et al. (2001) Clozapine, but not haloperidol, reverses social behavior deficit in mice during withdrawal from chronic phencyclidine treatment. Neuroreport 12: 11-15.

Qiao J, Gao J, Shu Q, et al. (2014) Long-lasting sensitization induced by repeated risperidone treatment in adolescent Sprague-Dawley Rats: A possible D2 receptor mediated phenomenon? Psychopharmacology (Berl) 231: 1649-1659.

Qiao J, Li H and Li M (2013) Olanzapine sensitization and clozapine tolerance: From adolescence to adulthood in the conditioned avoidance response model. Neuropsychopharmacology 38: 513-524.

Qin R, Chen Y and Li M (2013) Repeated asenapine treatment produces a sensitization effect in two preclinical tests of antipsychotic activity. Neuropharmacology 75C: 356-364.
Remington G and Kapur S (2010) Antipsychotic dosing: How much but also how often? Schizophr Bull 36: 900-903.

Renoir T, Pang TY and Lanfumey L (2012) Drug withdrawal-induced depression: Serotonergic and plasticity changes in animal models. Neurosci Biobehav Rev 36: 696-726.

Samaha AN, Reckless GE, Seeman P, et al. (2008) Less is more: Antipsychotic drug effects are greater with transient rather than continuous delivery. Biol Psychiatry 64: 145-152.

Samaha AN, Seeman P, Stewart J, et al. (2007) "Breakthrough" dopamine supersensitivity during ongoing antipsychotic treatment leads to treatment failure over time. J Neurosci 27: 2979-2986.

Seeman P (2008) Dopamine D2(high) receptors moderately elevated by bifeprunox and aripiprazole. Synapse 62: 902-908.

Seeman P, Weinshenker D, Quirion R, et al. (2005) Dopamine supersensitivity correlates with $\mathrm{D} 2^{\text {High }}$ states, implying many paths to psychosis. Proc Natl Acad Sci USA 102: 3513-3518.

Shapiro DA, Renock S, Arrington E, et al. (2003) Aripiprazole, a novel atypical antipsychotic drug with a unique and robust pharmacology. Neuropsychopharmacology 28: 1400-1411.

Shu Q, Hu G and Li M (2014) Adult response to olanzapine or clozapine treatment is altered by adolescent antipsychotic exposure: A preclinical test in the phencyclidine hyperlocomotion model. $J$ Psychopharmacol 28: 363-375.

Spielewoy C and Markou A (2003) Withdrawal from chronic phencyclidine treatment induces long-lasting depression in brain reward function. Neuropsychopharmacology 28: 1106-1116.

Sun T, Hu G and Li M (2009) Repeated antipsychotic treatment progressively potentiates inhibition on phencyclidine-induced hyperlocomotion, but attenuates inhibition on amphetamine-induced hyperlocomotion: Relevance to animal models of antipsychotic drugs. Eur J Pharmacol 602: 334-342.

Sun T, Zhao C, Hu G, et al. (2010) Iptakalim: A potential antipsychotic drug with novel mechanisms? Eur J Pharmacol 634: 68-76.

Swalve N and Li M (2012) Parametric studies of antipsychotic-induced sensitization in the conditioned avoidance response model: Roles of number of drug exposure, drug dose, and test-retest interval. Behav Pharmacol 23: 380-391.

Tadokoro S, Okamura N, Sekine Y, et al. (2012) Chronic treatment with aripiprazole prevents development of dopamine supersensitivity and potentially supersensitivity psychosis. Schizophr Bull 38: 1012-1020.

Turrone P, Remington G, Kapur S, et al. (2005) Continuous but not intermittent olanzapine infusion induces vacuous chewing movements in rats. Biol Psychiatry 57: 406-411.

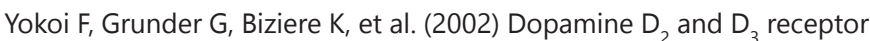
occupancy in normal humans treated with the antipsychotic drug aripiprazole (Opc 14597): A study using positron emission tomography and [11c]raclopride. Neuropsychopharmacology 27: 248-259.

Zhang C and Li M (2012) Contextual and behavioral control of antipsychotic sensitization induced by haloperidol and olanzapine. Behav Pharmacol 23: 66-79.

Zhao C and Li M (2012) Neuroanatomical substrates of the disruptive effect of olanzapine on rat maternal behavior as revealed by C-Fos immunoreactivity. Pharmacol Biochem Behav 103: 174-180.

Zhao C, Sun T and Li M (2012) Neural basis of the potentiated inhibition of repeated haloperidol and clozapine treatment on the phencyclidine-induced hyperlocomotion. Prog Neuropsychopharmacol Biol Psychiatry 38: 175-182.

Zocchi A, Fabbri D and Heidbreder CA (2005) Aripiprazole increases dopamine but not noradrenaline and serotonin levels in the mouse prefrontal cortex. Neurosci Lett 387: 157-161. 